\title{
IMPORTANCE OF MOTIVATION IN LEARNING ENGLISH LANGUAGE
}

\section{Nagham Oudah Alhamdawee ${ }^{1}$}

\footnotetext{
${ }^{1}$ Al- Iraqia University - College of Education for Women- Department of English Language - Iraq E-mail: eeye93@gmail.com
}

\begin{abstract}
Around the world, motivation plays a controlling role in the process of attempting to learn a certain division of study; even in learning a specific language, motivation and its basic types and theories must be studied by both the teacher and the learner, its role and effect on the learning process inside and outside of L2 classrooms. Teachers of a second language also play an important role in motivating and assisting their students in improving the type of motivation they have in order to develop their abilities in learning the language they wish to learn. So, the purpose of this research is to identify motivation with its various types and theories as defined by Gardner and Dorney, as well as to discuss teachers' roles in developing motivation in their students and assisting them in the process of learning a second language.
\end{abstract}

Key Words: motivation, Language Learning, teacher role. 


\section{دور التهفيز في تعلم اللغة الانكليرية}

\section{المدرس المساعد: نغم عودة جاسم1}

\section{1 الجامعة العر اقية ـ كلية التربية للبنات ـ قسم اللغة الانكليزية بريد الكتروني: eeye93@gmail.com}

HNSJ, 2022, 3(1); https://doi.org/10.53796/hnsj3154

$$
\text { تاريخ القبول: 2021/12/27م }
$$

\begin{tabular}{|c|}
\hline المستخلص \\
\hline 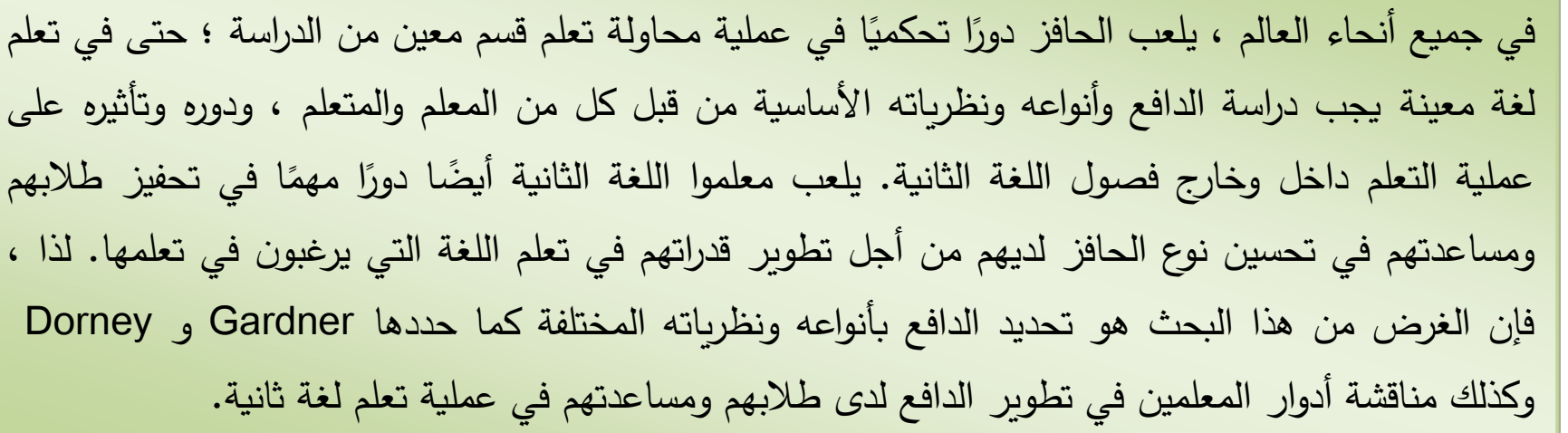 \\
\hline
\end{tabular}




\section{Introduction}

Learning a language is not easy; the learner must have a desire to learn that language and must work hard to achieve this desire, which is also known as motivation. The learner's desire to learn a second language may be motivated by a desire to achieve a specific goal, such as traveling to a foreign country, communicating with people outside his country, or having a good job. All of these factors are referred to as motivation, and they are the driving forces behind learning a second language.

Researchers and specialists in English language learning were interested in the topic of Motivation, and many of them assigned different definitions to the term. Gardnr and Dorney are the ones who put the definitions and identify the various types of motivation. The first to ground motivation research in a social psychological framework were Robert Gardner and Wallace Lambert. They also established scientific research procedures and introduced standardized assessment techniques and instruments, resulting in high research standards and the maturation of L2 motivation research. Dorney (1994, p.3)

\section{Literature review:}

Beginning in the 1990s, linguists and those who are interested in Language learning began to look for areas of motivation to understand its impact on language learning. In 1998, Denis and Qi Ze took the lead in discussing motivation and its role in language learning.

(Gardner 1985, p.10) indicated that motivation is an important factor in learning a specific language, and he defined it as "the combination of efforts with the desire to achieve the goal of learning that language." Motivation also facilitates the learner in obtaining basic language skills such like vocabulary, grammar, and pronunciation, which are part of the four skills of reading, writing, speaking, and listening. (as cited in Alizadih, 2016)

There are three distinct stages in the history of motivation in foreign teaching and learning, according to Dörnyei, 2011). (as cited in Guerrero 2014), beginning with The Social Psychological Period (1959-1990): The emphasis of this period was on the importance of language learners' attitudes and feelings toward L2 communities and the L2. This period witnessed Gardner's work in Canada. Gardner (2010) stated that motivation is a complex construct that does not have a simple or one definition; he stated that a motivated person is someone who sets a goal and works hard to achieve it (as cited in Guerrero 2014: 96).

Gardner proposed the majority of the theories in L2 motivation during this time period. Despite criticism from other researchers in this field, Gardner's theories have clearly served as the foundation and starting point for other researchers to better understand motivation in the field of L2 and other fields Gardner's bilingualism should be noted. His research and findings were influenced by the context in Canada. The emphasis on the attitudes of Individual attitudes toward both the L2 and the L2 community are unlikely to be transferrable applicable to other monolingual situations.

The second Stage is The Cognitive-Situated Period (1990's): This period intended to return the investigation's focus to the psychological field, emphasizing primarily cognition (or mental processes.) The learning contexts and needs of students and teachers in the classroom were deemed more important than the community and the environment social setting. This was not to say that the social and psychological 
findings were incorrect or ignored - in fact, the idea was to broaden previous theories while taking into account different cognitive perspectives.

There was a lot of interest in researching task-based instruction in the L2 field during this same cognitive-centered period. Dörnyei (2002) defines an instructional task as a "discreet unit of situated learning behaviors" (p. 139) pertaining to the task's goal and outcomes. This made the analysis of motivation in this field less difficult because Dörnyei's motivational theory incorporates previous aspects proposed by Gardner, but most importantly because this theory takes into account specific aspects within the pedagogical process (Dörnyei \& Ushioda, 2011), (as cited in Dörnyei, 2002) then proposed trait and state motivation. Trait motivation refers to an individual's motivation, whereas state motivation refers to a more specific or temporary learner motivation.

During this period, there is a clear shift in understanding of L2 motivation from a broad to a more specific perspective. This is not to dismiss previous theories in the social and psychological period-rather; it serves as the foundation for further research into areas where L2 motivation has not previously been studied. It is also interesting to see how Gardner's instrumental and integrative terms have served as a foundation for other terms that included more aspects of the learner, such as Dörnyei's (1994) three level theory and Tremblay et altrait/state's motivation terms. Furthermore, as opposed to the previous period's focus on attitudes toward the L2, there was a greater interest in learners and their learning experiences during this period.

The third period which is known as The Process-Oriented Period: This time period offers three key perspectives on L2 motivation:

The first was proposed by Williams and Burden (as cited in Dörnyei \& Ushioda, 2011) and included two terms: (1) Engagement motivation: desires, intentions, decisions; and (2) Engagement motivation: feelings, behavior during the learning process.

1- Ushioda (as cited in Dörnyei \& Ushioda, 2011) concentrated on the learner's shortterm motivation. This theory emphasized motivation during the learners' experiences (positive L2 experiences in the past, experiences relevant to their learning process) along with motivation directed toward the learner's future plans (personal goals, priorities, incentives)

2- Dörnyei and Otto's theories (as cited in Dörnyei \& Ushioda, 2011) were the most comprehensive among those proposed during this time period. Their strategy was divided into two stages: (1) Action stage: goals translate into intentions and accomplishments; and (2) Motivational stage: motivational forces pre-actional (e.g., goal setting), actional (e.g., registering for a language class), and post-actional (e.g., goal achievement) (e.g., external feedback or personal beliefs). (Guerrero. 2015. p 99);

There are four kinds of motivation :( intrinsic motivation and extrinsic motivation) and (Integrative \& instrumental motivation).

\section{Intrinsic and Extrinsic Motivation}

Intrinsic motivation is defined as "the innate proclivity to seek novelty and challenges, to stretch and exercise one's Capacities, to explore, and to learn" (Ryan \& Deci, 2000, p. 70). Intrinsic motivation is the most important type of motivation. However, the majority of people's actions are not intrinsically motivated. Extrinsic motivation, on the 
other hand, "involves doing an activity to achieve a separable consequence, whether tangible or otherwise" (Deci, Olafsen, \& Ryan, 2017, p. 2). Students who are intrinsically motivated are more likely to persevere with difficult problems and learn from their mistakes and slips (Walker, Greene, \& Mansell, 2006).

Engaging in behaviors for the purpose of experiencing joy and/or satisfaction is an example of intrinsic motivation (Dörnyei, 1998). People who are intrinsically motivated appear to "engage in activities for their own sake" rather than for externally derived rewards (Deci, 1975, p. 23). Extrinsic motivation is defined as a proclivity to participate in activities or achieve a high grade (Vansteenkiste, Lens, \& Deci, 20). There are various types of extrinsic motivation that vary in terms of self-determination, external regulation, interjected regulation, identified regulation, and integrated regulation are the levels of self-determination from low to high (Ryan \& Deci, 2000).

\section{Integrative \& instrumental motivation}

Gardner and Lambert (1972) distinguish two types of motivation: integrative and instrumental. Integrative motivation entails learning a language with the intention of participating in its people's culture. And instrumental motivation implies or suggests that a learner learns a language in support of a goal related to occupation or another useful motive. These two types of motivation have the ability to influence and control the process and outcome of learning. Cook (2000) considers Gardner and Lambert's integrative and instrumental motivation to be a useful and effective factor in second language learning.

Gardner (1985) and Ellis (1994) also introduce the aforementioned types of motivation; he demonstrated that the former occurs when the student wishes to join or be a part of a specific crowd and culture. The latter occurs when the learner anticipates numerous advantages that he intends to gain from learning a specific language. When these two types of motivation are compared, Ellis (1994) believes that the Integrative motivation is the best and perfect motivation. He considers integrative motivation to be more competent and well-organized.

Students who lack instrumental or integrative motivation will face problems and difficulties learning and gaining knowledge of a second language in the classroom, and learning the language will be difficult for them in general (Cook, 2000).

\section{Role of motivation in learning English language}

The importance of motivation in learning any language, including English, cannot be overstated. According to Ditual, R.C (2012), learners who have a positive attitude toward English language learning are highly motivated both instrumentally and interactively. He also claimed that external factors have no effect on learner motivation.

Engin (2009) discovered that instrumental motivation is based on a pragmatic approach, whereas integrative motivation is based on personal willingness and desire to achieve something through a study on the types of motivation required to learn a foreign language. Moiinvaziri. M (2009) disagreed with the researchers who thought instrumental motivation was important for EFL learning. He concluded that both instrumental and integrative motivation are important in English language learning. According to Al-Otaibi (2004), motivated learners can learn a foreign language more effectively and can bear high costs and make sacrifices in order to achieve their goals in learning L2. According to Brown (2001), motivation refers to the intensity of one's 
inner drive to learn. A learner with an integrative orientation is one who is learning L2 for social and cultural purposes. The motivation to achieve the goal can be strong or weak.

While Al - Hazemi H. (2000), said that a strong desire for L2 learning contributes significantly to achieving a high level of competence and success in achieving learners' language learning goals. Following the findings of four studies on L2 achievement, Lai (1999) concluded that Chinese students in Hong Kong were more career oriented and instrumentally motivated.

According to Ditual (2012), highly motivated learners who have positive attitudes toward learning English must be both instrumentally and interactively motivated. Chang (2010) stated that the class group influenced learners' motivation and must make them feel relaxed with motivated classmates, and he added that zinstrumental motivation is more important than integrative motivation in EFL learning.

According to Al-Otaibi (2004), motivated learners devote a significant amount of time to achieving their goals in learning a foreign language, and motivated learners can also learn a language more effectively than unmotivated ones. Learners with a strong desire to learn a language, according to Al-Hazemi (2000), can achieve a high level of competence in the target language.

According to Macintyre (1999), a safe classroom climate is necessary for motivation, and learners feel comfortable learning a language in this idea condition. According to Good and Brophy (1994), motivation cannot be developed in a difficult classroom, and teachers must create an effective learning environment for their students. They went on to say that effective language learning takes place in a relaxed and friendly environment.

\section{The teacher's role in motivating his students}

It is essential to discuss the relationship between teachers and students since it's an important factor in establishing a relaxed atmosphere in the classroom. When teachers believe their teaching is valued, they will work hard to succeed and support good student results. As a result, students will be more motivated and their language performance can be improved. Dornyei (2001:160) identifies four types of motivational aspects of teachers' motivation in this regard.

To begin, there is the intrinsic component, which refers to a strong inner desire to teach people, transfer information, and develop the community. Dornyei (2001:161) believes that intrinsic motivation is the most important factor in teacher motivation. Second, social contextual influences have an impact on teacher motivation. Walker and Symons (1997; cited in Dornyei, 2001: 160) state that "the environment plays a fundamental role in job motivation, that is, it is the work, not the Worker, which affects persistence and

performance." Dinham and Scott (2000) classified contextual influences into two categories that influence teachers' satisfaction in different ways: macro and micro factors.

Dornyei (2001) defines the third aspect of teacher motivation as the temporal dimension of teacher motivation. According to Dornyei (2001:178), teacher motivation is related not only to an interest in teaching but also to a desire to teach as a career.

Finally, any negative influences on teacher motivation are addressed as a final factor. These include five motivational factors: inherent stress, a lack of teacher 
autonomy (such as curriculum development), a lack of training, a repetitive context with limited opportunities for improvement, and an insufficient job structure. Overall, motivation approaches share a common feature, which is based on the idea that all learners are motivated to learn in appropriate situations, which can be set by the teacher in the classroom (Dornyei, 2001:167-176).

Brophy (1985:180) from the other hand lists eight concrete ways in which negative expectancy-driven Teacher behavior can reduce student motivation:

1- Easily giving up on students with low expectations (e.g. not waiting long enough for their answer.

2- Criticizing them more frequently for failure.

3- Reducing the frequency with which they are praised after success.

4- Inappropriate praise (e.g. after routine responses(

5- Failing to provide any feedback in response to their responses.

6- Placing them at the far end of the room

7- Paying less attention to them or interacting with them less frequently in general.

8- Showing less affection for them or less interest in them as individuals

\section{Important aspects in Motivation}

Motivation is the most complex and difficult issue for language teachers today. Motivation is an abstract and hypothetical term that we use to explain why leaners, in these case students, think and behave the way they do. Dörnyei (2001) defines motivation as "the force that moves a person to initiate an action and to continue until the goals are met." Our past actions, and especially how we interpret our past successes and failures, determine our current and future behavior, and we will be more motivated to do something on our own rather than something that is forced upon us. Nobody can deny that our personal likes and dislikes (attitudes) play a significant role in determining whether or not we will do something. Even the brightest students are unlikely to persevere long enough to gain any truly useful knowledge if they are not sufficiently motivated.

Many students with learning disabilities, it has been observed, are not highly motivated to improve their academic skill deficiencies. Individuals with severe and pervasive skill problems frequently develop a generalized pattern of negative attitudes and avoidance behavior toward schools, teachers, class work, books, and so on. Of course, such avoidance can also interfere with learning. The problem may be exacerbated if the student discovers appealing alternatives to school-related learning activities, such as daydreaming, involvement in disruptive behaviors with peers, and so on.

\section{Conclusion}

We conclude from this paper that motivation is the most important factor in actions, willingness, and goals. These needs, wants, or desires may be acquired as a result of cultural, social, or lifestyle influences, or they may be innate. An individual's motivation can be influenced by external forces (extrinsic motivation) or by inner feelings (intrinsic motivation). The distinction between intrinsic and extrinsic motivation is determined by the actions taken. Intrinsic motivation refers to an internal desire to complete a task, whereas extrinsic motivation refers to completing a task in order to receive some kind of reward.

On the other hand, instrumental motivation means the student learns a language to pass an examination or to get a job while Integrative motivation means learning the 
language to participate in the culture of its people.

On the other hand, instrumental motivation means that the student learns a language in order to pass an exam or get a job, whereas integrative motivation means that the student learns the language in order to participate in the culture of its people.

Furthermore, we conclude that motivation is one of the most important factors influencing language learners' success or failure in learning the language, and motivation is the key to successfully learning English, and interest in learning English is one of the most important factors influencing how well students learn a foreign language.

Motivation explains how teachers can increase their students' motivation to learn. While students may have an innate desire to learn, the teacher's external support has a significant impact on students' learning. The teacher's role in motivation includes, but is not limited to, creating a learning environment.

Finally, understanding motivation provides us with a wealth of information about human nature. It explains why we set goals and strive for success and power, why we want psychological intimacy and biological sex, and why we feel emotions like fear, anger, and compassion.

\section{References.}

Adelman, H. S., \& Taylor, L. (1983). Enhancing Motivation for Overcoming Learning and Behavior Problems. Journal of Learning Disabilities, 16(7), 384-392.

Doi:10.1177/002221948301600702

Al-Hazemi, H. (2000). Lexical Attrition of Some Arabic Speakers of English as a Foreign Language: a Study of Word Loss. Internet TESL J [Serial online] Available from: http://iteslj.org/Articles/Al-Hazemi-Attrition/

Al-Otaibi, G. (2004). Language Learning Strategy Use among Saudi EFL Students and Its Relationship to Language Proficiency Lever, Gender, and Motivation [PhD Dissertation]. Indiana (PA): Indiana University of Pennsylvania.

Berridge, K. C. (2004004). Motivation concepts in behavioral neuroscience. Physiology \& Behavior, 81(2), 179-209. Doi:10.1016/j.physbeh.2004.02.004. Boston, MA: McGraw-Hill, pp. 24-45. Working Papers in Applied Linguistics (London: Thames Valley University), 4, 43-69.

Brophy, J.E. (1985) Teachers' expectations, motives and goals for working with problem students. In Ames, C. and Ames, R. (eds), Research on Motivation in Education: The Classroom Milieu. Orlando, FL: Academic Press: 175-214. Burgueño R. \& Sicilia A. and et al (2017). Academic motivation scale revised. Inclusion of integrated regulation to measure motivation in initial teacher education.anales de psicología, vol. 33 http://dx.doi.org/10.6018/analesps.33.3.249601

Cook, V. (2000). Linguistics and second language acquisition. Beijing: Foreign Language Teaching and Research Press and Macmillan Publishers Ltd.

Deci, E., Olafsen, A., \& Ryan, R. (2017). Self-determination theory in work organizations: The State of a science. Annual Review of Organizational Psychology and Organizational behavior ,4, 19-43. https://doi.org/10.1146/annurev-orgpsych-032516$\underline{113108}$

Deci, E. L. (1975). Intrinsic motivation. New York: Plenum Press. 
Deci, E. L., Ryan, R. M., \& Williams, G. C. (1996). Need satisfaction and the self Regulation of learning. Learning and Individual Differences, 8, 165-183.

Doi:10.1016/S1041-6080(96)90013-8

Deci, E. L., \& Ryan, R. M. (2000). The "What" and "Why" of goal pursuits: Human needs and the self-determination of behavior. Psychological Inquiry, 11(4), 227-268. http://doi.org/10.1207/S15327965PLI1104_01

Ditual, R.C. (2012), The Motivation For and Attitude Towards Learning English. Asian EFL Journal, Volume 63.

Dörnyei, Z. (1998). Motivation in second and foreign language learning. Language

Teaching,31(3), 117-135. https://doi.org/10.1017/s026144480001315x

Dornyei, Z. (1994) motivation and Motivating in the Foreign Language Classroom. The Modern Language Journal, 78,3, pp. 273-284.

Dörnyei, Z. (2005). The Psychology of the language learner: individual differences in second language acquisition. Mahwah, NJ. [etc.]: Lawrence Erlbaum. Dörnyei, Z., \& Ushioda, E. (2001). Teaching and researching motivation. New York, NY: Longman.

Ellis, Rod. (1994). The Study of Second Language Acquisition. Oxford: Oxford University Press.

Gardner, R.C. (1985). Social Psychology and Second Language Learning. London BNM/.,MEdward Arnold.

Guay, F., Ratelle, C. F., \& Chanal, J. (2008). Optimal learning in optimal contexts: The Role of self-determination in education. Canadian Psychology, 49, 233-240.

Harter, S. (1999). The construction of the self: A developmental perspective. New York:The Guilford Press.

Latham, Gary P, Editors : David Whetten \& Anne S. Huff (2007), "Work Motivation ",Sage Publications, Inc. United States of America.

MacIntyre, P. D. (1999). Language Anxiety: A Review of the Research for Language Teachers. In Young, D. J. (ed.). Affect in Foreign Language and Second Language Learning.

Macklem, L. G (2015).Boredom in the Classroom: Addressing Student Motivation, Self- Regulation, and Engagement in Learning.Switzerland: Springer International Publishing Switzerland

Moiinvaziri, M. (2009). Motivational Orientation in English Language Learning: A Study of Iranian Undergraduate Students. Available at:

thttp://www.usingenglish.com/articles/moal-orientation-in-english-learning.html Moskovsky, C, G., \& Alrabai, F. A. (2009). Intrinsic Motivation in Saudi Learners of English as a Foreign Language. The Open Applied Linguistics Journal, 21-10.

Olsson .M. F. (2008)."Developments in the Psychology of Motivation ".Nova publisher, Inc. New York.

Rud A. G. Ed: Olusola O. Adesope( 2019), "Contemporary Technologies In Education: Student Engagement, Motivation, And Learning"

Ryan, R., \& Deci, E. (2000). Self-determination theory and the facilitation of intrinsic motivation ,Social development, and well-being. American Psychologist, 55(1), 6878.https://doi.org/10.1037/0003-066x.55.1.68

Sánchez-Oliva, D., Viladrich, C., Amado, D., González-Ponce, I., \& García-Calvo, T. (2014). Prediction of positive behaviors in Physical Education: A Self-Determination 
Theory perspective. Revista de Psicodidáctica, 19(2), 387-406. http://doi.org/10.1387/RevPsicodidact.7911

Shahar, G., Henrich, C. C., Blatt, S. J., Ryan, R. M., \& Little, T. D. (2003). Interpersonal

Relatedness, self-definition, and motivational orientation during adolescence: A Theoretical and empirical investigation. Developmental Psychology, 39, 470-483. Doi:10.1037/0012-1649.39.3.470

Vallerand, R. J. (2000). Deci and Ryan's self-determination theory: A view from the Hierarchical Model of Intrinsic and Extrinsic Motivation. Psychological Inquiry, 11(4), 312-318.

Vansteenkiste, M., Lens, W., \& Deci, E. L. (2006). "Intrinsic versus extrinsic goal contents in selfdetermination theory: Another look at the quality of academic motivation". Educational Psychologist,41(1), 19-31.

Walker, C., Greene, B., \& Mansell, R. (2006). "Identificat ion with academics, intrinsic/extrinsic mot ivation, and self-Efficacy as predictors of cognitive engagement". In Learning and Individual Differences, 16(1), pp. 1-12

Ziahosseini, M., \& Salehi, M. (2008). An Investigation of the Relationship between Motivation and Language Learning Strategies. Pazhuhesh-e Zabanha-ye Khareji, 41, 85-107. 